\title{
The Influences of Concentrate Extract Properties and Ethanol Addition Amount on the Ethanol Precipitation Process of Salvia Miltiorrhiza
}

\author{
Chenhao Wang*, Xiangning Liu*, Xingchu Gong\# \\ Pharmaceutical Informatics Institute, College of Pharmaceutical Sciences, Zhejiang University, Hangzhou, China \\ Email: "gongxingchu@zju.edu.cn
}

How to cite this paper: Wang, C.H., Liu, X.N. and Gong, X.C. (2021) The Influences of Concentrate Extract Properties and Ethanol Addition Amount on the Ethanol Precipitation Process of Salvia Miltiorrhiza. Pharmacology \& Pharmacy, 12, 191-207. https://doi.org/10.4236/pp.2021.1210017

Received: August 9, 2021

Accepted: October 9, 2021

Published: October 12, 2021

Copyright $\odot 2021$ by author(s) and Scientific Research Publishing Inc. This work is licensed under the Creative Commons Attribution International License (CC BY 4.0).

http://creativecommons.org/licenses/by/4.0/

\begin{abstract}
In this work, 10 batches of Salvia miltiorrhiza concentrate were prepared and purified with ethanol precipitation process. Dry matter content, $\mathrm{pH}$ value, conductivity and water content of the concentrates and supernatants were all determined. When more ethanol was used in ethanol precipitation, the $\mathrm{pH}$ value of the supernatant generally increased, but dry matter content, water content, and the conductivity decreased. Multivariate linear models were built with the most determination coefficient values greater than 0.7. More than $80 \%$ of stachyose was removed in the ethanol precipitation process. The removal rate of fructose, raffinose and sucrose were all higher than $30 \%$. When ethanol addition amount increased, the purity of phenolic acids in the supernatant increased, but the retention of lithosperimic acid and salvianolic acid $B$ decreased. The conductivity and $\mathrm{pH}$ value of concentrated extract show relatively small influences on ethanol precipitation indices. When fructose, raffinose, or stachyose contents in the concentrated extract were high, the retention rate of phenolic acids tends to be low on most occasions. The purity and retention rate of phenolic acids in the supernatants were also affected by the purity of phenolic acids in the concentrated. The sugar contents in the concentrate are suggested to be monitored in industry because they significantly affect ethanol precipitation process indices.
\end{abstract}

\section{Keywords}

Ethanol Precipitation Process, Salvia Miltiorrhiza, Nature of Concentrate, Sugars, Stepwise Regression

${ }^{\star}$ These authors contributed equally to this work. 


\section{Introduction}

Ethanol precipitation is a commonly used purification process in Chinese medicine industry [1]. The advantages of ethanol precipitation process include simple operation, safe solvent, and high impurity removal rate [2]. The ethanol precipitation process mainly realizes the impurity removal by reducing the solubility of impurities by adding ethanol. Impurities mainly include water-soluble sugars, proteins, and salts [3], etc. Increasing the relative density of concentrate, increasing the amount of ethanol, and decreasing the refrigeration temperature are conducive to improve the removal rate of water-soluble sugars, such as glucose, sucrose, maltose, raffinose [3] [4] [5], etc.

However, ethanol precipitation process will also lead to the loss of active ingredients [6] [7]. By optimizing the parameters of ethanol precipitation process, such as system $\mathrm{pH}$, ethanol amount, ethanol adding speed and ethanol concentration [8] [9], refrigeration temperature [10], and refrigeration time [11], it is possible to reduce the loss of active ingredients. In addition, controlling the properties of concentrated extract before ethanol precipitation also affects the loss of active ingredients [12]. For example, Yan et al. [13] found that the contents of Danshensu, caffeic acid and salvianolic acid B in Guanxinning concentrate can significantly affect the retention of active ingredients after ethanol precipitation. Zhang et al. [14] found that the $\mathrm{pH}$ value and caffeic acid content of salvia miltiorrhiza concentrate can significantly affect the retention rate of phenolic acids in ethanol precipitation. However, the studies mentioned above did not investigate the effects of sugars in concentrated extract on the purification of ethanol precipitation.

Salvia miltiorrhiza is a medicinal herb for promoting blood circulation and removing blood stasis. Its main active ingredients are phenolic acids and tanshinones. Salvia miltiorrhiza extract is usually purified by ethanol precipitation process. In this study, taking the ethanol precipitation process of Salvia miltiorrhiza extract as an example, multiple batches of Salvia miltiorrhiza concentrate were treated with ethanol precipitation process. The contents of sugars and phenolic acids before and after ethanol precipitation were determined. Some other material properties including dry matter content, $\mathrm{pH}$ value, and conductivity were also determined. Mathematical models were built to investigate the influence of the composition of the concentrate and the ethanol addition amount on the ethanol precipitation process. Finally, the critical indices of Salvia miltiorrhiza concentrate were determined.

\section{Materials and Methods}

\subsection{Experimental Reagents}

Ethanol (analytical pure) was purchased from Shanghai Lingfeng Chemical Reagent Co., Ltd. Methanol (Chromatographic pure) was purchased from Merck Life Sciences (Shanghai) Co., Ltd. Acetonitrile (chromatographic purity) was 
purchased from Merck Life Sciences (Shanghai) Co., Ltd. Fructose (batch No. A0282904) was obtained from ACROS organics, Belgium. Glucose (batch No. 20141121) reference substance was purchased from Sinopharm Chemical Reagent Co., Ltd. Sucrose (batch No. WXBB0906V) was purchased from sigma Aldrich company of the United States. Danshensu sodium (batch No. 160120), protocatechuic aldehyde (batch No. 160125), caffeic acid (batch No. 180103), rosmarinic acid (batch No. 150901), lithospermic acid (batch No. 190530), salvianolic acid B (batch No. 200107), raffinose (batch No. 180923) and stachyose (batch No. 171129) were purchased from Shanghai Ronghe Pharmaceutical Technology Co., Ltd. Deionized water. Anhydrous methanol (80080418) was purchased from Sinopharm Chemical Reagent Co., Ltd. Karl Fischer Reagent (k820873) was purchased from Hangzhou ChenTong Materials Co., Ltd. Deionized water was produced with an ultra-pure water machine (Milli-q, Millipore Company).

\subsection{Preparation of Concentrate Samples}

Salvia miltiorrhiza of $200 \mathrm{~g}$ was put into the decocting pot (FT-30H, Zhushuixi Electric). Then water was added with liquid-solid mass ratio of $8: 1$. Salvia miltiorrhiza was soaked for $30 \mathrm{~min}$ before decoction. Salvia miltiorrhiza was then decocted for $30 \mathrm{~min}$ and the extract was collected. After that, Salvia miltiorrhiza was decocted again to obtain aqueous extract. The extracts were combined. After concentration, Salvia miltiorrhiza concentrate was obtained with a relative density of $1.15-1.25$. The weight and volume of a concentrate were both measured to obtain the density value of the concentrate. Ten different batches of Salvia miltiorrhiza concentrates were prepared.

\subsection{Preparation of Supernatant Samples}

Each batch of Salvia miltiorrhiza concentrate was put into conical bottles. A 95\% (v/v) ethanol solution was added drop wisely with a pump (YZ15, Changzhou weixier Fluid Technology Co., Ltd.) under magnetic stirring (HJ-2A, Xicheng Xinrui Instrument Factory). The mass ratio of ethanol solution to concentrated extract (ECR) was 1.2, 1.5, 2.0 and 3.0, respectively. After adding ethanol, stirring was kept for 20 minutes and the conical bottles were sealed with sealing film. In pre-experiments, it is found that supernatant composition changed little after refrigeration for more than 12 hours. Therefore, the conical bottles were refrigerated for more than 12 hours at $4^{\circ} \mathrm{C}$. After that, the supernatant was collected.

\subsection{Determination of Dry Matter, Conductivity and pH of Concentrated Extract and Supernatant}

A weighing bottle was dried in a drying oven (XMTD-8222, Shanghai Jinghong Experimental Equipment Co., Ltd., IBAO-250, stukai instrument equipment (Shanghai) Co., Ltd.) at $105^{\circ} \mathrm{C}$ for $1 \mathrm{~h}$. Then its weight $\left(m_{1}\right)$ was determined with 
an electronic balance (AB204-N, METTLER TOLEDO Shanghai Co., Ltd.). An appropriate amount of concentrated extract was added. The total weight of the bottle and concentrated extract was weighed $\left(m_{2}\right)$. The weighing bottle was dried in the oven at $105^{\circ} \mathrm{C}$ for $3 \mathrm{~h}$. Then it was taken out and weighed. The total weight of the bottle and dried extract was $m_{3}$. After that, the weighing bottle was dried in the oven at $105^{\circ} \mathrm{C}$ for $1 \mathrm{~h}$ and weight again. The new weight was $m_{4}$. If the difference between $m_{3}$ and $m_{4}$ was less than $5 \mathrm{mg}$, the drying was stopped. The dry matter can be calculated with Formula (1). Dry matter value was determined three times in parallel.

$$
\text { Dry matter }=\frac{m_{4}-m_{1}}{m_{2}-m_{1}}
$$

$0.50 \mathrm{~g}$ concentrated extract sample was weighed and diluted with deionized water to $50 \mathrm{~mL}$. Its conductivity was measured with a conductivity meter (DDBJ-350, Hangzhou Qiwei Instrument Co., Ltd.). The sample conductivity of ethanol precipitation supernatant can be directly measured by the conductivity meter. The $\mathrm{pH}$ of supernatant and concentrate were measured by a $\mathrm{pH}$ meter (SevenMulti series, METTLER TOLEDO Shanghai Co., Ltd.).

\subsection{Determination of Phenolic Acid Contents in Concentrated Extract and Supernatant}

Preparation of test solution: a $10 \mathrm{~mL}$ volumetric flask was taken. An appropriate amount of concentrated extract or supernatant was added. The sample was diluted with $70 \%$ methanol solution (V/V) and shaken well. The concentrated extract sample was then centrifuged at $12,000 \mathrm{rpm}$ for $10 \mathrm{~min}$. Then it was filtered with a $0.22 \mu \mathrm{m}$ filter membrane to obtain the test solution. The ethanol precipitation supernatant sample can be directly filtered with a $0.22 \mu \mathrm{m}$ filter membrane to obtain the test solution.

Preparation of reference solution: a $10 \mathrm{~mL}$ volumetric flask was taken. 2.65 $\mathrm{mg}, 0.88 \mathrm{mg}, 1.89 \mathrm{mg}, 1.18 \mathrm{mg}, 4.58 \mathrm{mg}$ and $8.49 \mathrm{mg}$ of Danshensu sodium, protocatechuic aldehyde, caffeic acid, rosmarinic acid, lithospermic acid and salvianolic acid B were accurately weighed with analytical balances (AB204-N, AE240, METTLER TOLEDO Shanghai Co., Ltd.), respectively. 70\% methanol solution $(\mathrm{V} / \mathrm{V})$ was added to dissolve the references. The solution was shaken well to prepare a mixed stock solution.

Phenolic acid contents were determined with an HPLC system with a UV detector (FL5090, Zhejiang Fuli Analytical Instrument Co., Ltd.; Agilent 1100, Agilent Technology Co., Ltd.). Chromatographic conditions and detector parameters were taken from literature [15]. An Extend-C18 $(250 \mathrm{~mm}) \times 4.6 \mathrm{~mm}, 5$ $\mu \mathrm{m})$ chromatographic column was used. The mobile phase was composed of $0.1 \%$ formic acid in water (A) and acetonitrile (B). Elution gradient was shown in Table 1. Column temperature was $25^{\circ} \mathrm{C}$. The flow rate was $1 \mathrm{ml} / \mathrm{min}$ and the detection wavelength was $281 \mathrm{~nm}$. Injection volume was $5 \mu \mathrm{L}$. The typical chromatogram obtained was shown in Figure 1. 


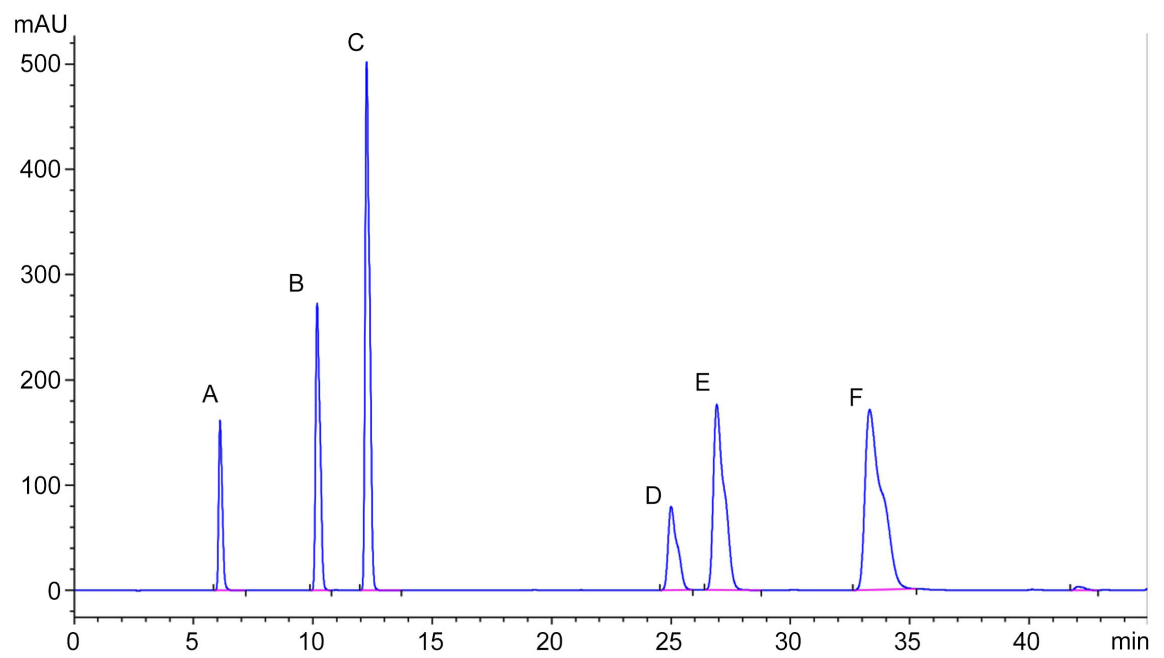

(a) standard

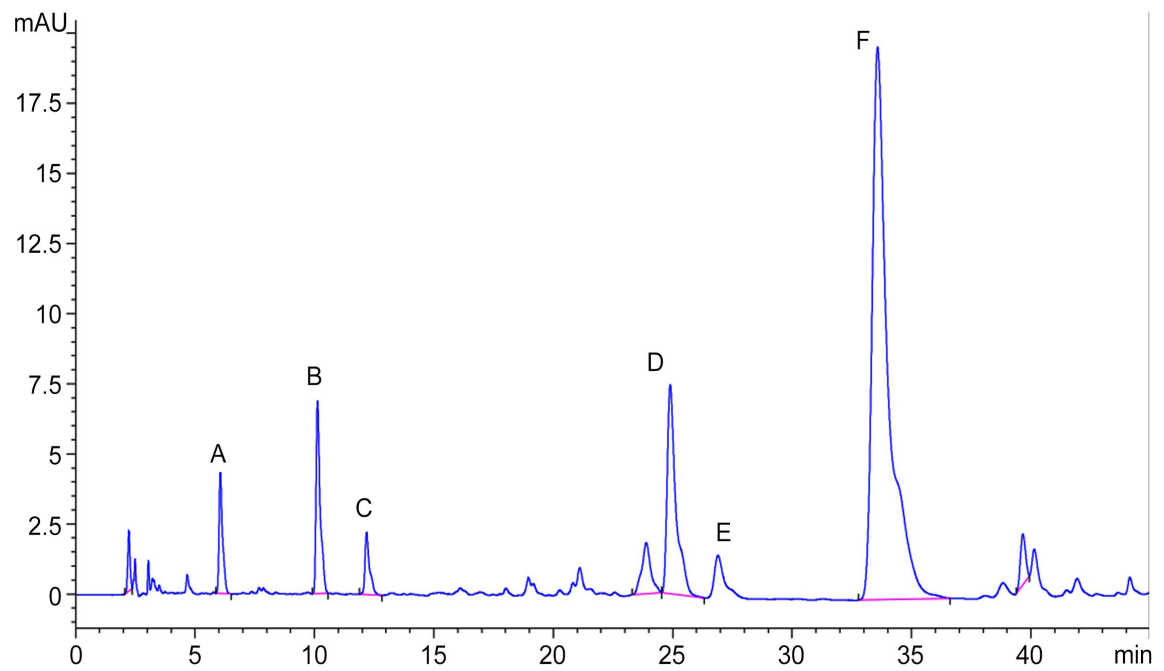

(b) concentrate extract

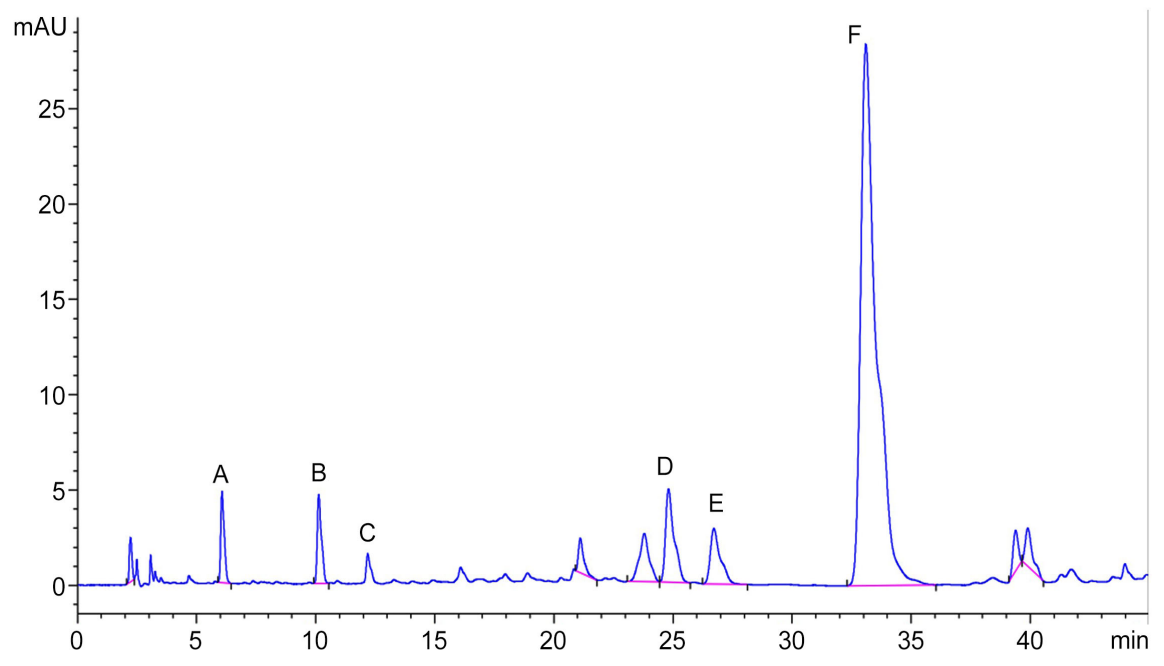

(c) supernatant

Figure 1. HPLC chromatogram of phenolic acids. A: Danshensu; B: Protocatechuic aldehyde; C: Caffeic acid; D: Rosmarinic acid; E: Lithospermic acid; F: Salvianolic acid B. 
Table 1. Elution gradient for the determination of salvianolic acids.

\begin{tabular}{ccc}
\hline Time (min) & Mobile Phase A (\%) & Mobile Phase B (\%) \\
\hline $0-10$ & $93-83$ & $7-17$ \\
$10-16$ & $83-79$ & $17-21$ \\
$16-32$ & $79-71$ & $21-29$ \\
$32-40$ & $71-65$ & $29-35$ \\
$40-44$ & $65-28$ & $35-72$ \\
$44-45$ & $28-25$ & $72-75$ \\
\hline
\end{tabular}

\subsection{Determination of Sugar Content in Concentrated Extract and Supernatant [16]}

Preparation of test solution: a $10 \mathrm{~mL}$ volumetric flask was taken. An appropriate amount of concentrated extract or supernatant was added. The sample was diluted with $80 \%$ acetonitrile solution $(\mathrm{V} / \mathrm{V})$ and shaken well. Then it was filtered with a $0.22 \mu \mathrm{m}$ filter membrane to obtain the test solution.

Preparation of reference stock solution: $4.99 \mathrm{mg}, 4.60 \mathrm{mg}, 4.06 \mathrm{mg}$ and 5.51 $\mathrm{mg}$ of fructose, sucrose, raffinose and stachyose were accurately weighed with analytical balances (AB204-N, AE240, METTLER TOLEDO Shanghai Co., Ltd.) respectively into a $5 \mathrm{~mL}$ volumetric flask. A small amount of deionized water was added to dissolve them. Then the volume was fixed with deionized water and shaken well to obtain the mixed reference stock solution.

Sugar contents were determined with an HPLC system with an ELSD detector (Agilent 1260, Agilent Technology Co., Ltd.). A Carbohydrate ES $(250 \mathrm{~mm} \times 4.6$ $\mathrm{mm}, 5 \mu \mathrm{m})$ Chromatographic column was used. The mobile phase was composed of water (A) - acetonitrile (B). Elution gradient was shown in Table 2. Column temperature was $25^{\circ} \mathrm{C}$. Injection volume was $5 \mu \mathrm{L}$. Flow rate was 0.6 $\mathrm{mL} / \mathrm{min}$. Evaporative light scattering detector atomizer (ELSD) temperature was $70^{\circ} \mathrm{C}$. Drift tube temperature was $60^{\circ} \mathrm{C}$. Nitrogen flow rate was $1.0 \mathrm{~L} / \mathrm{min}$. The typical chromatogram obtained was shown in Figure 2.

\subsection{Model Building}

The effects of ethanol precipitation were characterized with phenolic acid purity in the supernatant and phenolic acid retention after precipitation. They were calculated with Formulas (2) and (3) and considered as process indices.

$$
\text { Phenolic acid purity }=\frac{\text { Phenolic acid content }(\mathrm{mg} / \mathrm{g} \text { materials })}{\text { Dry matter }(\mathrm{mg} / \mathrm{g} \text { materials })} \times 100 \%
$$

Phenolic acid retention $=$

$\frac{\text { Phenolic acid content in supernatant } \times \text { Supernatant weight }}{\text { Phenolic acid content of concentrate } \times \text { Concentrate weight }} \times 100 \%$

The quantitative models were established by Formula (4) to correlate concentrated extract indices, ethanol addition amount, and process indices.

$$
Y=b_{0}+\sum_{i=1}^{n} b_{i} z_{i}+c x
$$




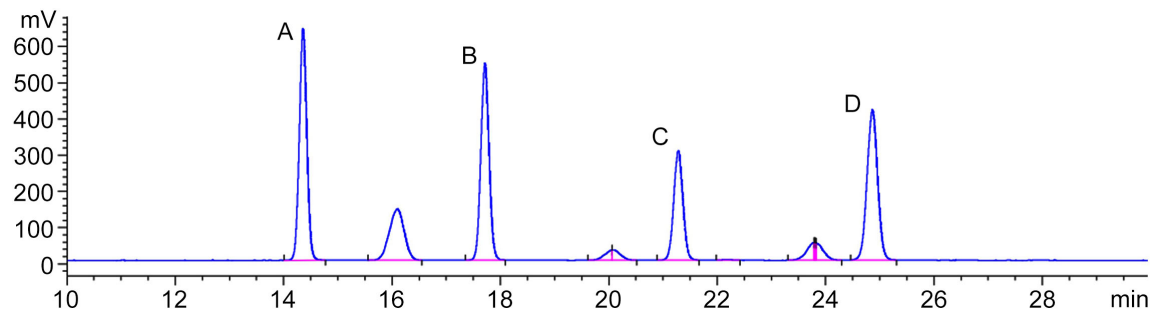

(a) standard

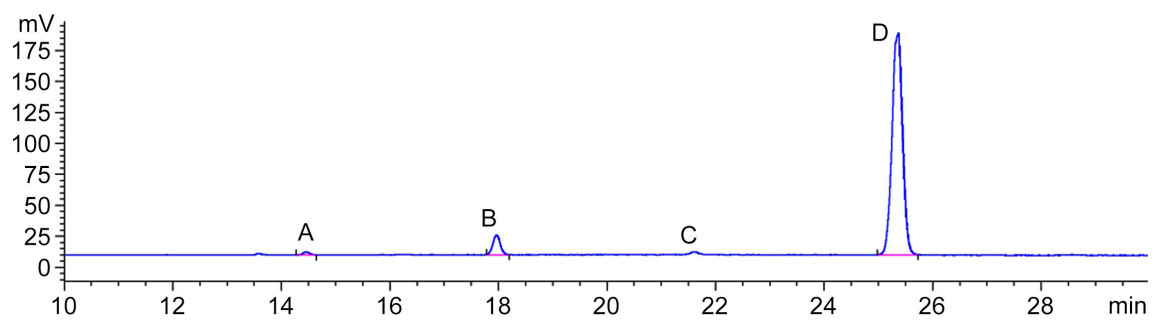

(b) concentrate extract

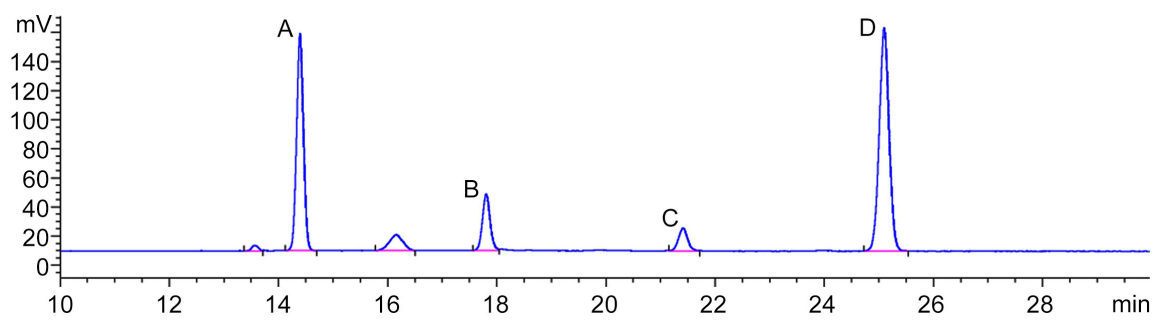

(c) supernatant

Figure 2. HPLC-ELSD chromatogram of sugars. A: Fructose; B: Sucrose; C: Raffinose; D: Stachyose.

Table 2. Elution gradient for the determination of seven sugars.

\begin{tabular}{ccc}
\hline Time (min) & Mobile Phase A (\%) & Mobile Phase B (\%) \\
\hline $0-5$ & $20-25$ & $80-75$ \\
$5-10$ & $25-35$ & $75-65$ \\
$10-28$ & $35-50$ & $65-50$ \\
$28-29$ & $50-80$ & $50-20$ \\
$29-39$ & 80 & 20 \\
$39-40$ & $80-20$ & $20-80$ \\
\hline
\end{tabular}

where $y$ was the process indices, $b_{0}$ was the constant term, $b_{i}$ and $c$ were the partial regression coefficients, $Z_{i}$ was a concentrate index, $n$ was the number of concentrate indices, and $X$ represent ECR. The model was simplified by stepwise regression, and the $\mathrm{P}$ values of moving in and moving out a term were both 0.05 .

\section{Experimental Results}

\subsection{Quality Index of Concentrate}

The dry matter content, $\mathrm{pH}$ value, and conductivity of ten batches of Salvia miltiorrhiza concentrate are shown in Table 3. Most of the dry matter content were 
more than $40.0 \%$. The $\mathrm{pH}$ value varied from $4.5-6.0$. The conductivity was between 4 and $8 \mathrm{mS} / \mathrm{cm}$.

Phenolic acid purity of each batch of concentrated extract is shown in Table 4. Salvianolic acid B was the component with the highest purity, and the purity were all more than $4 \%$. Followed by Danshensu and lithospermic acid, and their purity values were between $0.2 \%-0.6 \%$. The purity value of protocatechuic aldehyde and caffeic acid were lower than $0.1 \%$. The purity of rosmarinic acid varied from $0.1 \%$ to $0.8 \%$.

Sugar content of concentrated extract was calculated with Formula (5) and shown in Table 5. The content of stachyose was the highest, mostly more than $30.0 \%$. The contents of fructose and raffinose were low, mostly less than $1.0 \%$. The content of sucrose in each group varied greatly, ranging from $0.2 \%$ to $2.0 \%$.

$$
\text { Sugar content }=\frac{\text { Sugar concentration }(\mathrm{mg} / \mathrm{g} \text { materials })}{\text { Dry matter }(\mathrm{mg} / \mathrm{g} \text { materials })} \times 100 \%
$$

Table 3. Determination results of concentrate mass, dry matter, $\mathrm{pH}$ and conductivity.

\begin{tabular}{|c|c|c|c|}
\hline Medicinal Material Batch & Dry matter content (\%) & $\mathrm{pH}$ & Conductivity $(\mathrm{mS} / \mathrm{cm})$ \\
\hline 200525 & 43.84 & 5.290 & 4.88 \\
\hline 180927 & 41.50 & 5.377 & 4.16 \\
\hline 181001 & 41.91 & 4.659 & 6.47 \\
\hline 180901 & 42.66 & 5.132 & 5.98 \\
\hline 200501 & 41.70 & 5.354 & 4.22 \\
\hline 200502 & 43.36 & 5.283 & 5.08 \\
\hline 200503 & 40.17 & 5.564 & 5.98 \\
\hline 200504 & 36.27 & 5.432 & 4.96 \\
\hline 200505 & 45.01 & 5.541 & 7.37 \\
\hline 200506 & 46.07 & 5.213 & 4.32 \\
\hline
\end{tabular}

Table 4. Determination results of phenolic acid purity of concentrated extract.

\begin{tabular}{|c|c|c|c|c|c|c|}
\hline $\begin{array}{c}\text { Medicinal } \\
\text { Material Batch }\end{array}$ & Danshensu (\%) & $\begin{array}{c}\text { Protocatechuic } \\
\text { Aldehyde (\%) }\end{array}$ & $\begin{array}{c}\text { Caffeic Acid } \\
(\%)\end{array}$ & $\begin{array}{l}\text { Rosmarinic Acid } \\
(\%)\end{array}$ & $\begin{array}{l}\text { Lithospermic } \\
\text { acid (\%) }\end{array}$ & $\begin{array}{c}\text { Salvianolic Acid } \\
\text { B (\%) }\end{array}$ \\
\hline 200525 & 0.451 & 0.052 & 0.035 & 0.291 & 0.449 & 9.38 \\
\hline 180927 & 0.532 & 0.055 & 0.033 & 0.178 & 0.442 & 5.31 \\
\hline 181001 & 0.558 & 0.026 & 0.020 & 0.241 & 0.393 & 7.51 \\
\hline 180901 & 0.467 & 0.029 & 0.022 & 0.088 & 0.338 & 4.29 \\
\hline 200501 & 0.397 & 0.051 & 0.020 & 0.210 & 0.356 & 6.16 \\
\hline 200502 & 0.418 & 0.056 & 0.023 & 0.193 & 0.352 & 6.33 \\
\hline 200503 & 0.403 & 0.054 & 0.032 & 0.780 & 0.313 & 5.91 \\
\hline 200504 & 0.431 & 0.055 & 0.020 & 0.206 & 0.273 & 6.22 \\
\hline 200505 & 0.447 & 0.071 & 0.029 & 0.316 & 0.282 & 6.11 \\
\hline 200506 & 0.408 & 0.038 & 0.029 & 0.218 & 0.322 & 6.23 \\
\hline
\end{tabular}


Table 5. Determination results of sugar content in concentrated extract.

\begin{tabular}{ccccc}
\hline Medicinal Material Batch & Fructose (\%) & Sucrose (\%) & Raffinose (\%) & Stachyose (\%) \\
\hline 200525 & 0.195 & 1.937 & 0.310 & 34.45 \\
180927 & 0.700 & 0.166 & 0.532 & 40.50 \\
181001 & 1.123 & 0.359 & 0.408 & 31.68 \\
180901 & 0.912 & 0.168 & 0.205 & 25.38 \\
200501 & 0.278 & 0.417 & 0.446 & 48.91 \\
200502 & 0.376 & 1.647 & 0.519 & 38.90 \\
200503 & 0.318 & 0.286 & 0.400 & 31.38 \\
200504 & 0.355 & 1.659 & 0.337 & 30.44 \\
200505 & 0.282 & 1.775 & 0.368 & 34.88 \\
\hline
\end{tabular}

\subsection{Quality Index of Supernatant}

Dry matter content, $\mathrm{pH}$ value, conductivity and water content of the ethanol precipitation supernatants were determined and shown in Figure 3. Dry matter content, conductivity and water content decreased as ethanol addition amount increased. Supernatant $\mathrm{pH}$ value slightly increased as ethanol addition amount increased, and varied from 5.0 and 6.0. The conductivity ranged from 3 to 20 $\mathrm{mS} / \mathrm{cm}$. Dry matter content of a supernatant was less than $12 \%$. Water content of a supernatant was between $20 \%-35 \%$.

The phenolic acid purity values of ethanol precipitation supernatant samples are shown in Figure 4. Phenolic acid purity values increased as ethanol addition amount increased. Salvianolic acid B was the component with the highest purity, which ranged from $5.0 \%$ to $20 \%$. Most of other phenolic acid purity values were less than $2 \%$. Compared with that of concentrated extract, phenolic acid purity increased after ethanol precipitation. This phenomenon agreed well with those observed in previous works. The main reason is that a large amount of dry matter was removed in the ethanol precipitation process [6] [17].

Figure 5 shows the retention rate of phenolic acids. The retention rate of salvianolic acid B and lithospermic acid slightly decreased as ethanol addition amount increased. The retention rate of protocatechuic aldehyde and caffeic acid varied from $45.0 \%$ to $90.0 \%$. Most of rosmarinic acid retention rate values were above 50.0\%. Most of lithospermic acid, Danshensu and salvianolic acid B retention values were below $50 \%$.

Sugar content in dry matter is shown in Figure 6. With the addition of ethanol, fructose content and sucrose content generally increased, but stachyose content significantly decreased. At most occasions, stachyose content was much higher than that of other sugars. After ethanol precipitation, fructose content and sucrose content were less than $10 \%$ and $15 \%$, respectively. Raffinose content was less than $3 \%$. Stachyose content was always higher than $10 \%$. 


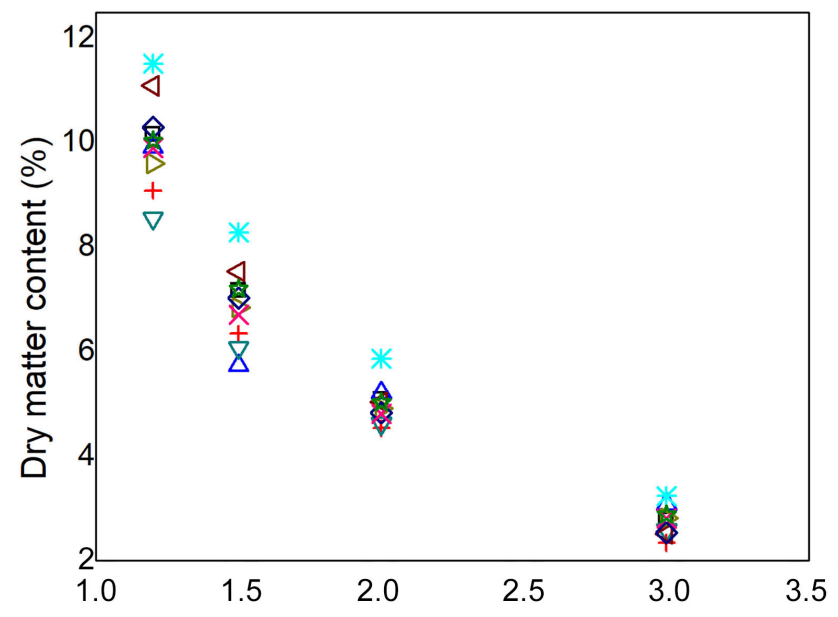

Mass ratio of ethanol to concentrated extract $(\mathrm{g} / \mathrm{g})$

(a) dry matter

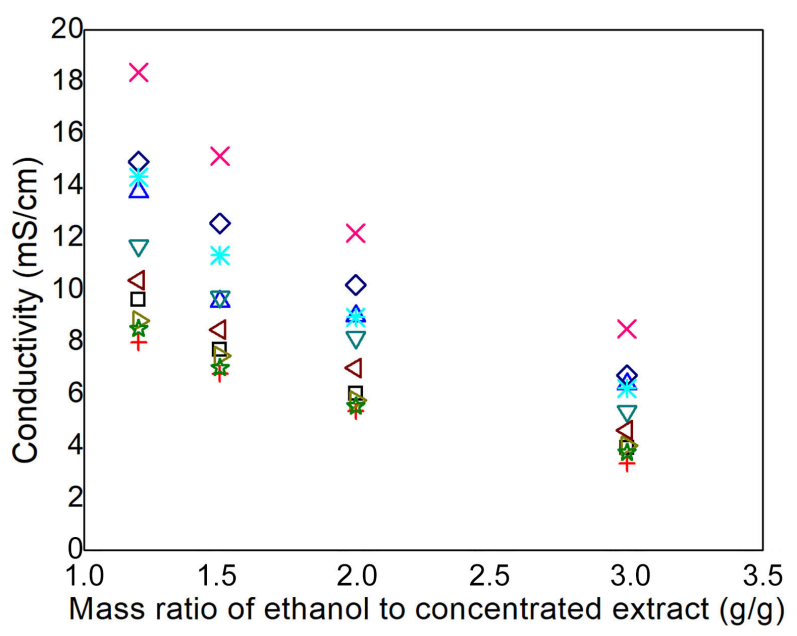

(c) conductivity

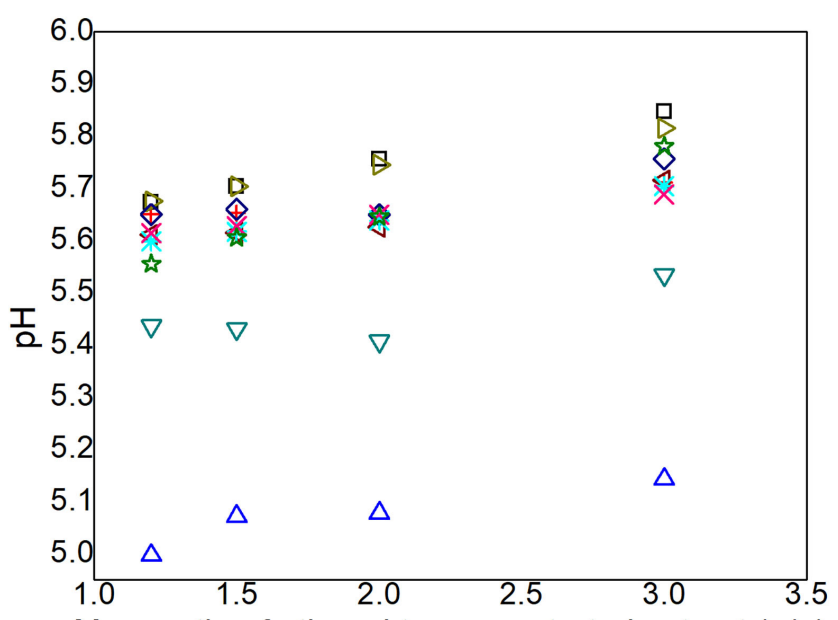

Mass ratio of ethanol to concentrated extract $(\mathrm{g} / \mathrm{g})$

(b) $\mathrm{pH}$

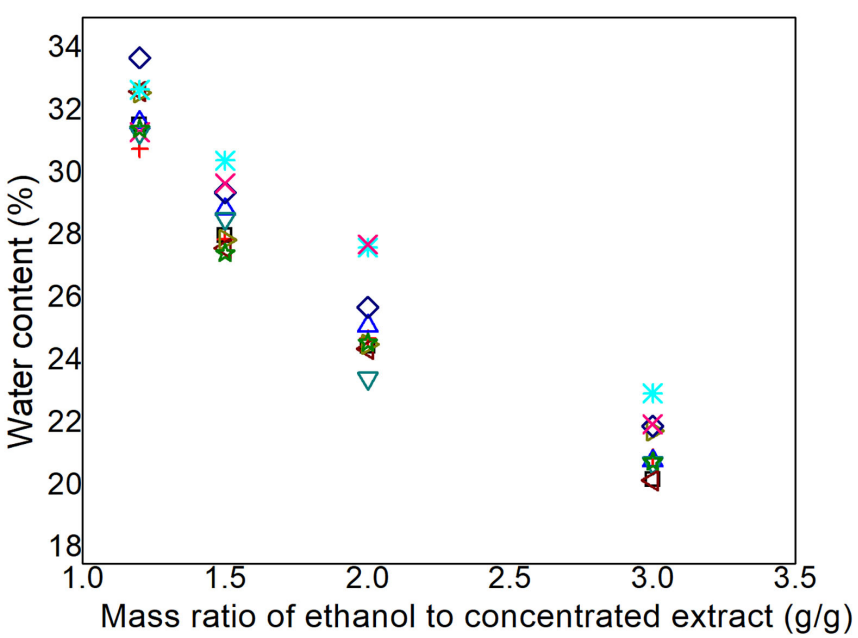

(d) water content

Figure 3. Dry matter content, pH value, conductivity and water content results of supernatant. $\square 200525 ;+180927 ; \triangle 181001$; $\nabla$ 180901; $\triangleleft 200501 ; \triangleright 200502 ; \diamond 200503 ; * 200504 ; X 200505 ;$ ‘ 200506.

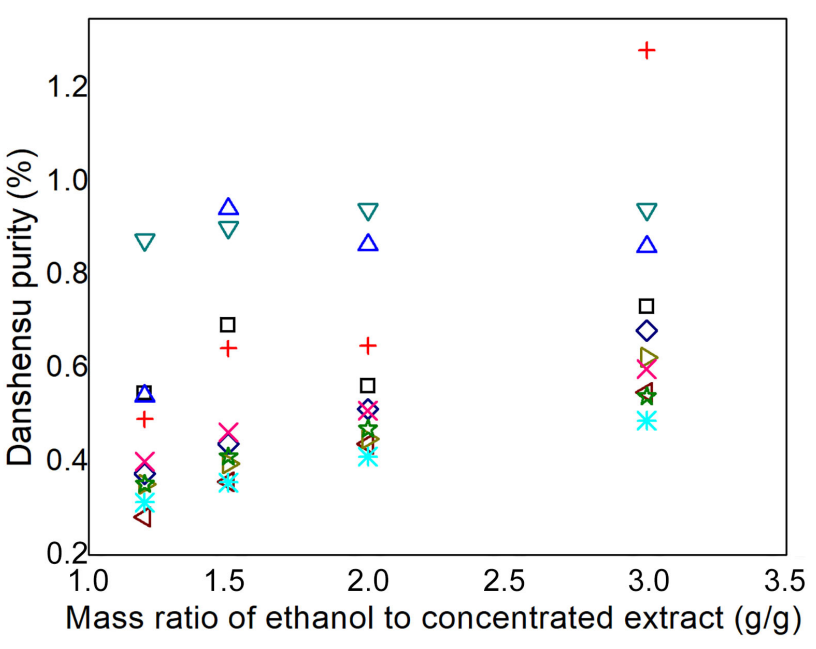

(a) Danshensu

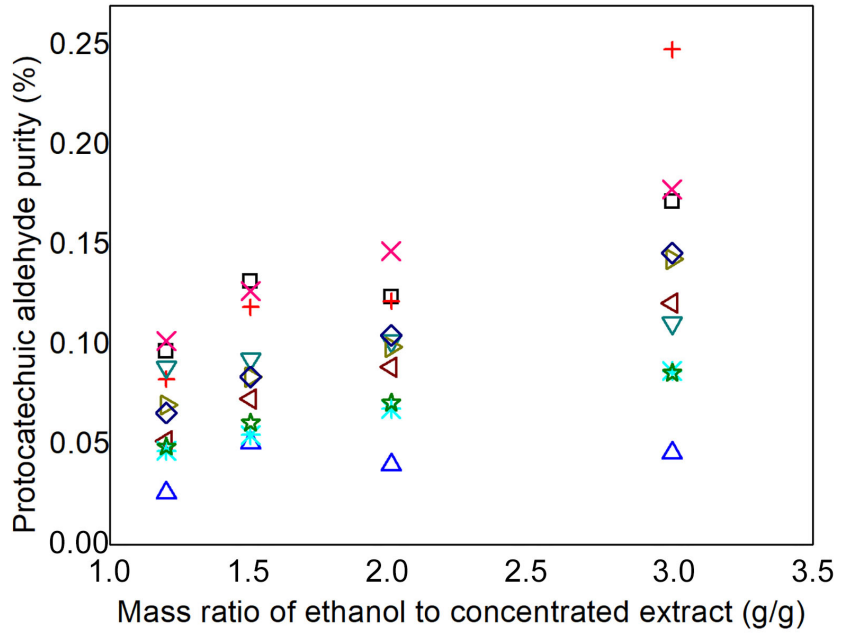

(b) protocatechuic aldehyde 


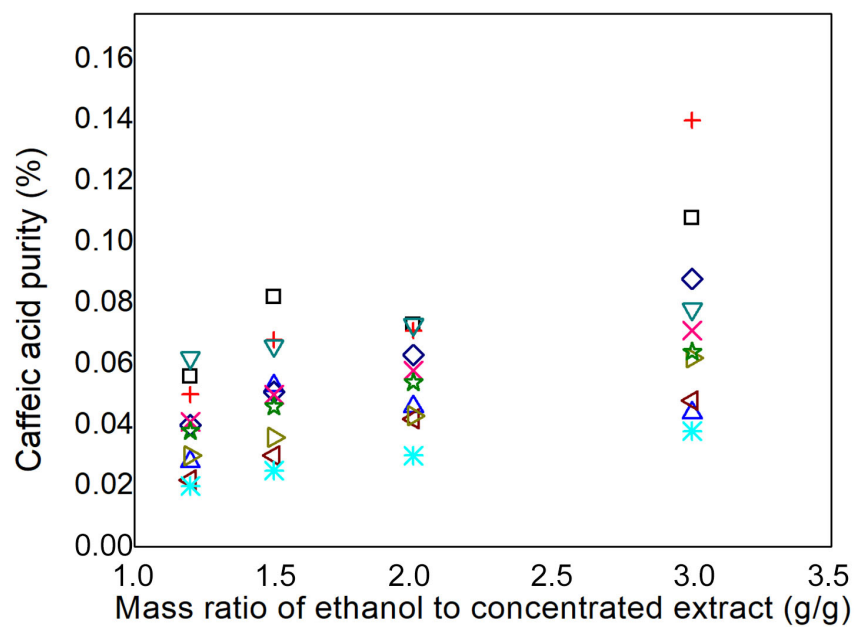

(c) caffeic acid

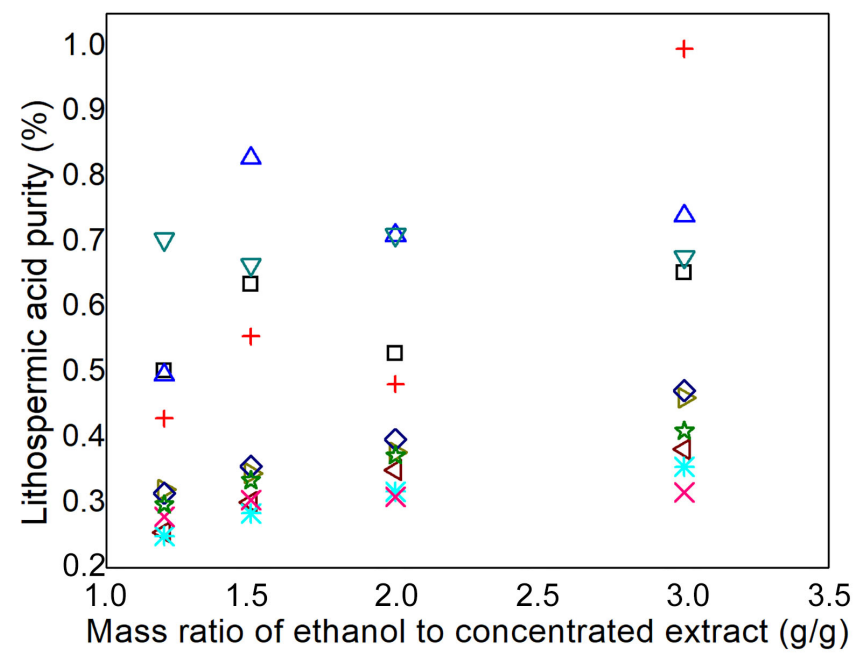

(e) lithospermic acid

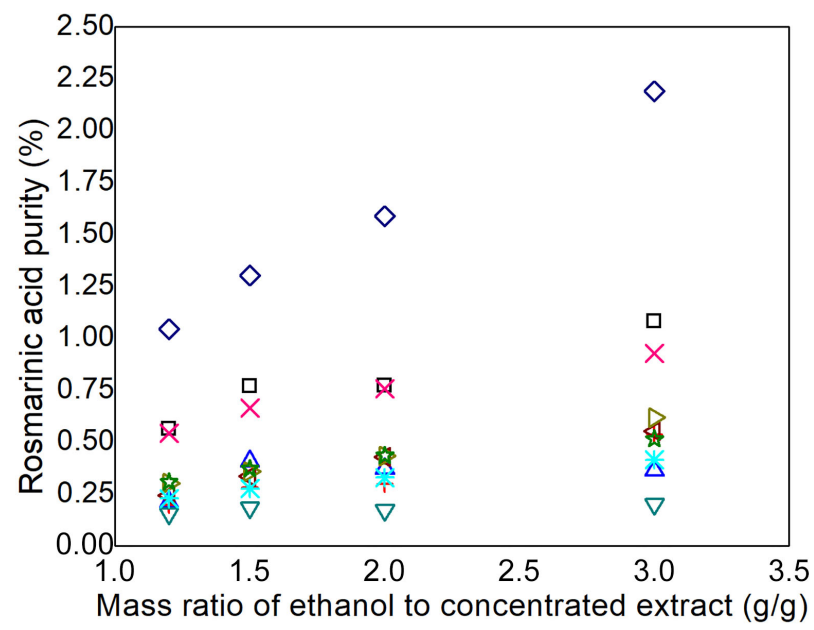

(d) rosmarinic acid

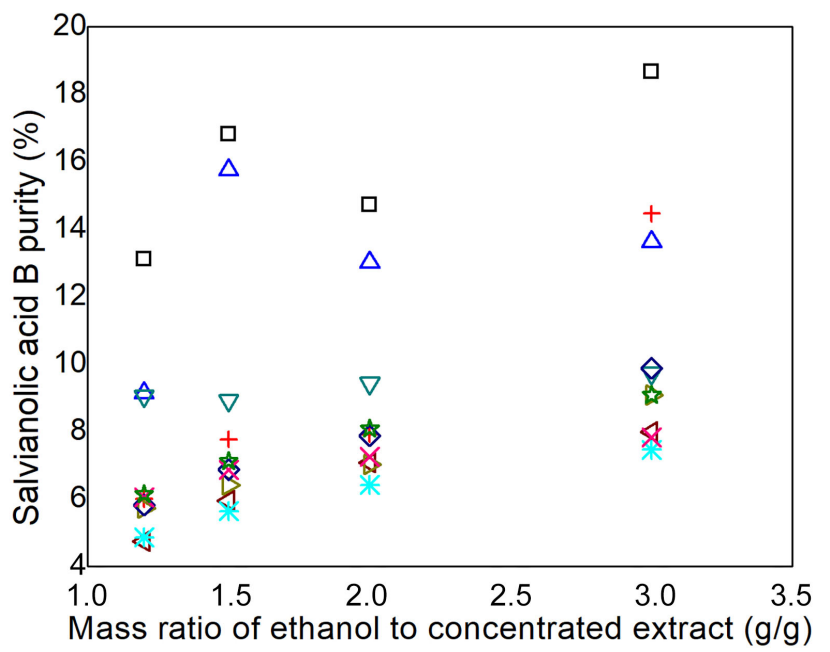

(f) salvianolic acid B

Figure 4. Phenolic acid purity of supernatant. $\square$ 200525; $+180927 ; \Delta 181001 ; \nabla$ 180901; $\triangleleft 200501 ; \triangleright 200502 ; \diamond 200503 ; \star$ 200504; X 200505; is 200506.

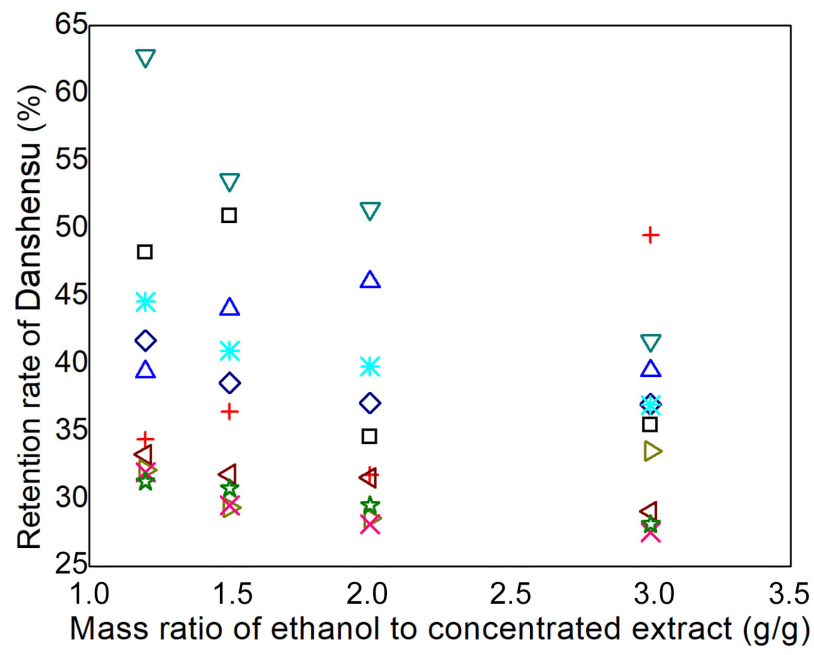

(a) Danshensu

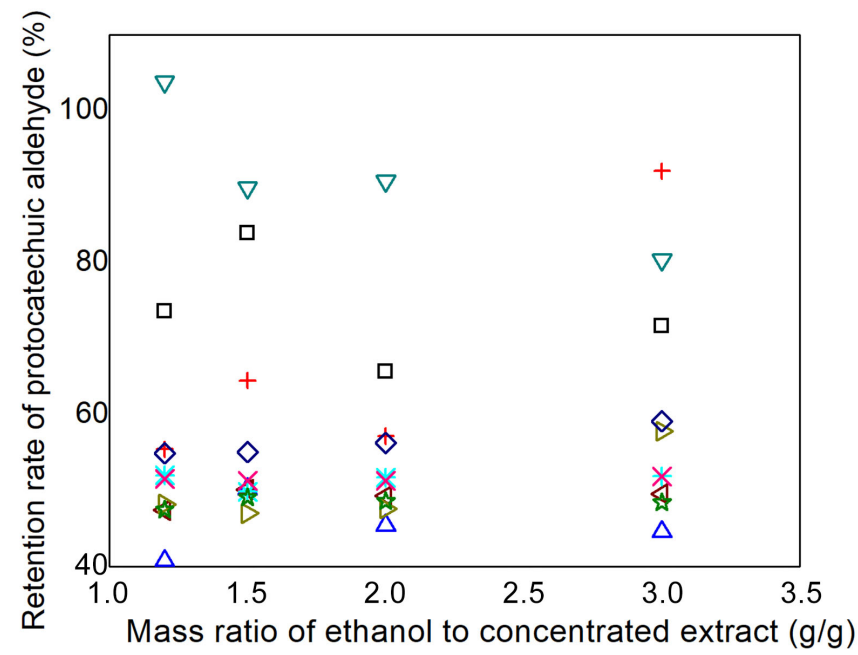

(b) protocatechuic aldehyde 


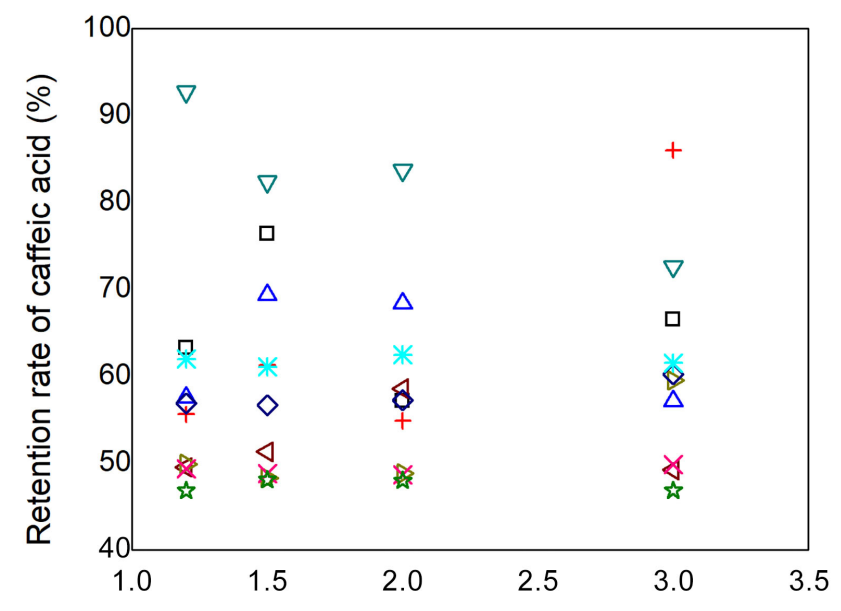

Mass ratio of ethanol to concentrated extract $(\mathrm{g} / \mathrm{g})$

(c) caffeic acid

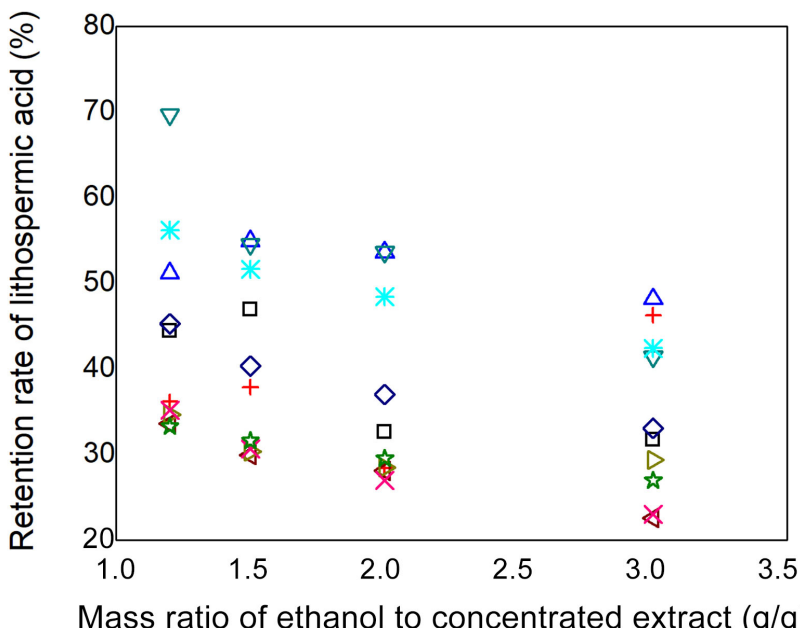

(e) lithospermic acid

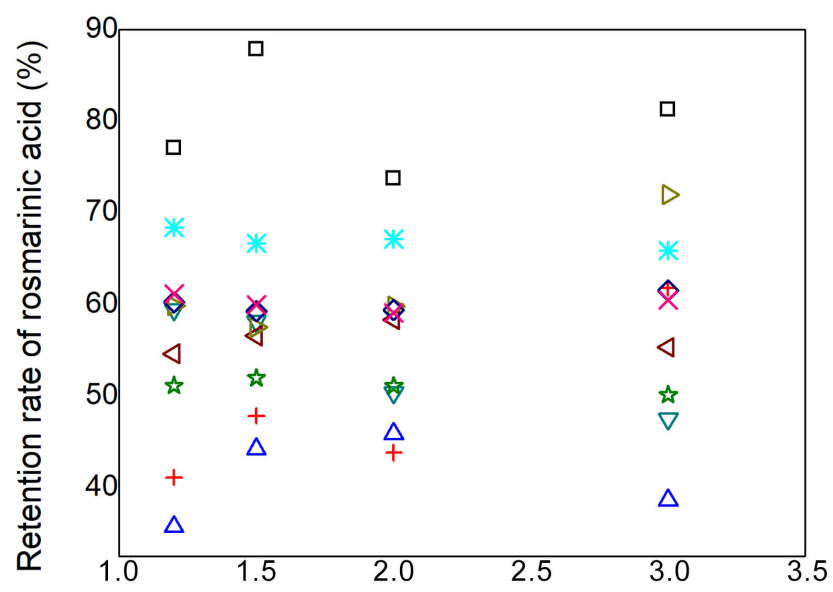

Mass ratio of ethanol to concentrated extract $(\mathrm{g} / \mathrm{g})$

(d) rosmarinic acid

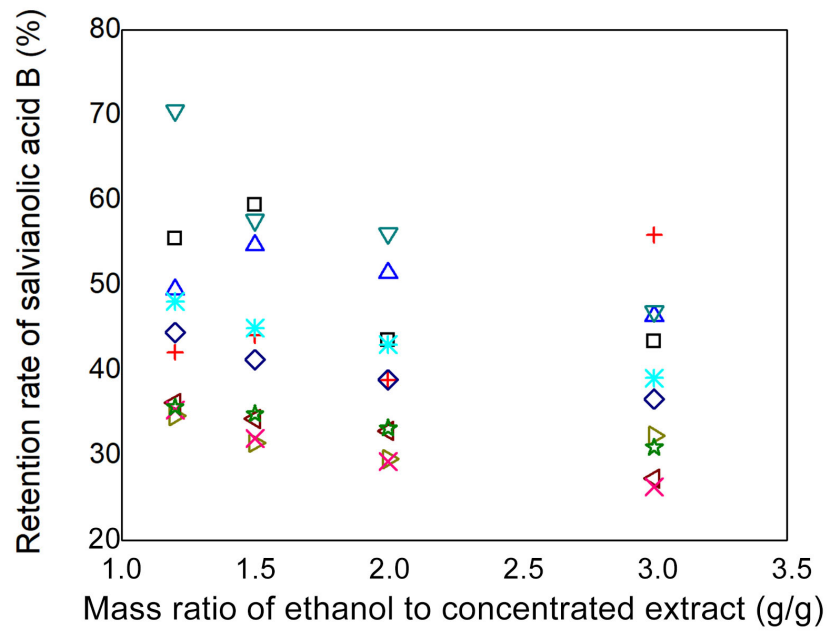

(f) salvianolic acid B

Figure 5. Phenolic acid retention results. $\square$ 200525; + 180927; $\triangle$ 181001; $\nabla$ 180901; $\triangleleft 200501 ; \triangleright 200502 ; \diamond 200503 ; *$ 200504; X 200505; is 200506.

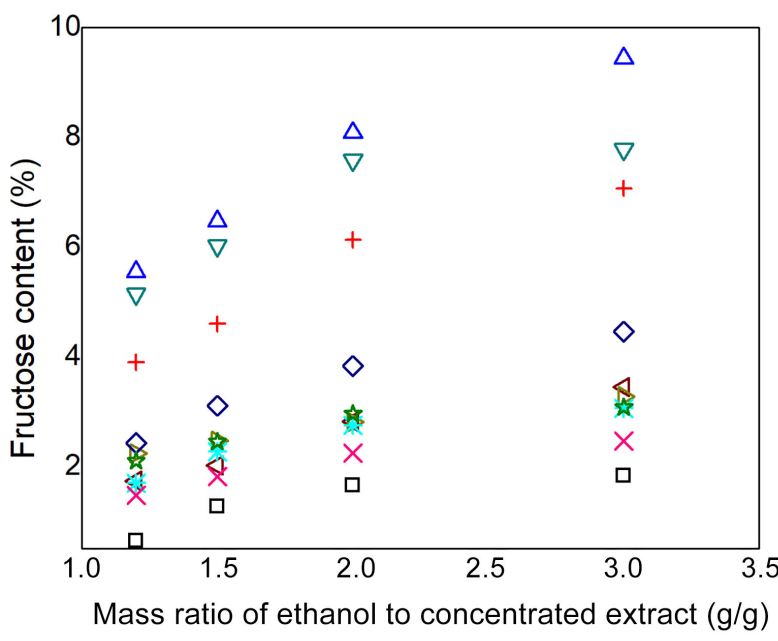

(a) fructose

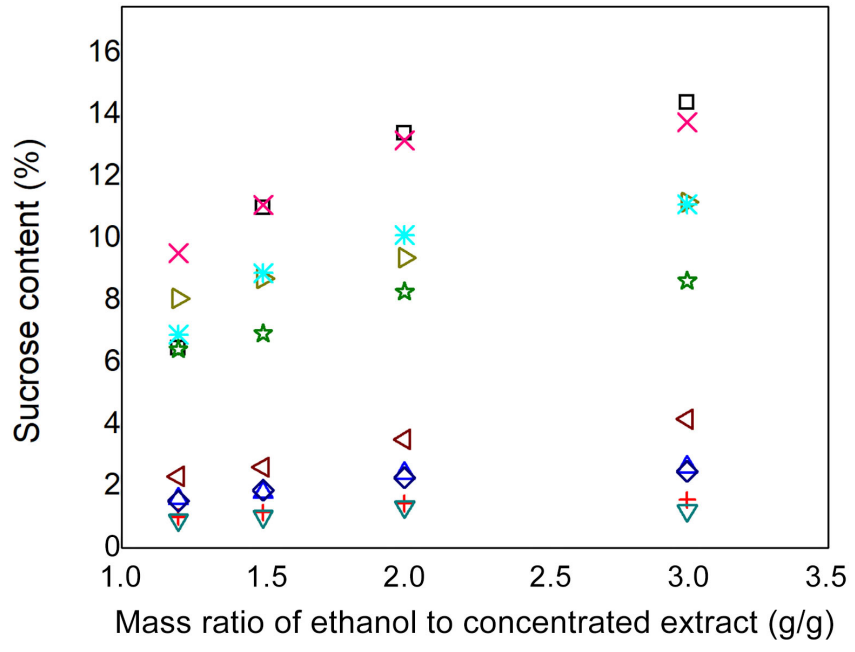

(b) sucrose 


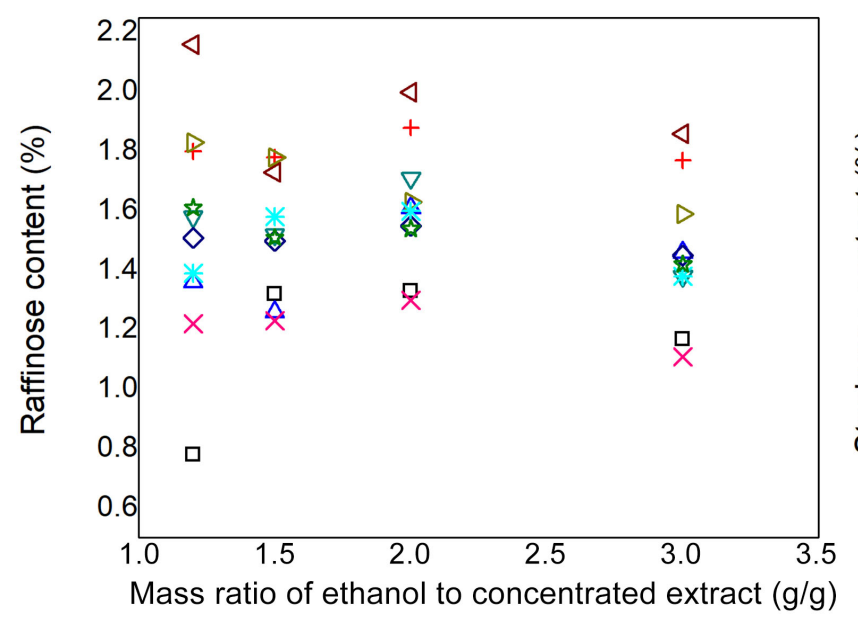

(c) raffinose

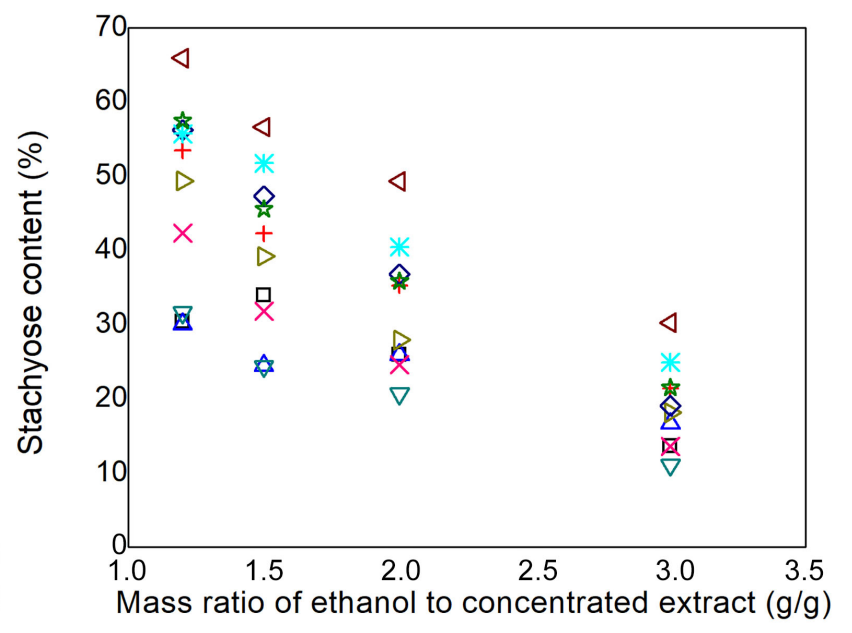

(d) stachyose

Figure 6. Determination results of sugar content in supernatant. $\square 200525 ;+180927 ; \triangle 181001 ; \nabla 180901 ; \triangleleft 200501 ; \triangleright$ 200502; $\diamond 200503 ;{ }^{*} 200504 ; \times 200505$; is 200506.

Sugar removal rate was also calculated and shown in Figure 7. All the sugars were removed partly. The removal rate of raffinose and stachyose increased as ethanol addition amount increased. Stachyose removal rate was more than $80 \%$. The removal rate of raffinose or sucrose was more than 50\%. Fructose removal rate varied among batches, ranging from $30.0 \%$ to $80.0 \%$.

\subsection{Modeling Analysis}

The quantitative models of process indices were established with Formula (4). The regression coefficients and variance analysis results of the models are shown in Table 6. The determination coefficient $\left(R^{2}\right)$ values of most models are between $0.70-0.90$, indicating that the model can explain most of the data variation.

Ethanol addition amount significantly affected most of process indices except the retention of protocatechuic aldehyde, caffeic acid and rosmarinus acid. The increase of ethanol addition amount can improve the purity of phenolic acids in the supernatant, but reduce the retention of lithosperimic acid and salvianolic acid $\mathrm{B}$. The conductivity and $\mathrm{pH}$ value of concentrated extract affected a small number of process indices.

Sucrose content was removed in model building. The increase of fructose content in the concentrated extract can improve the purity of Danshensu and lithospermic acid in the supernatant, but reduce the retention rate of rosmarinic acid in the supernatant. The increase of raffinose content in the concentrated extract can reduce the purity of protocatechuic aldehyde, lithospermic acid and salvianolic acid B in the supernatant, and also reduce the retention rate of protocatechuic aldehyde and caffeic acid. The increase of stachyose content in concentrate reduced the retention of caffeic acid, rosmarinic acid, lithospermic acid, and salvianolic acid B. It can be concluded that higher content of fructose, raffinose, and stachyose in the concentrated extract generally led to lower retention rate of phenolic acids. 


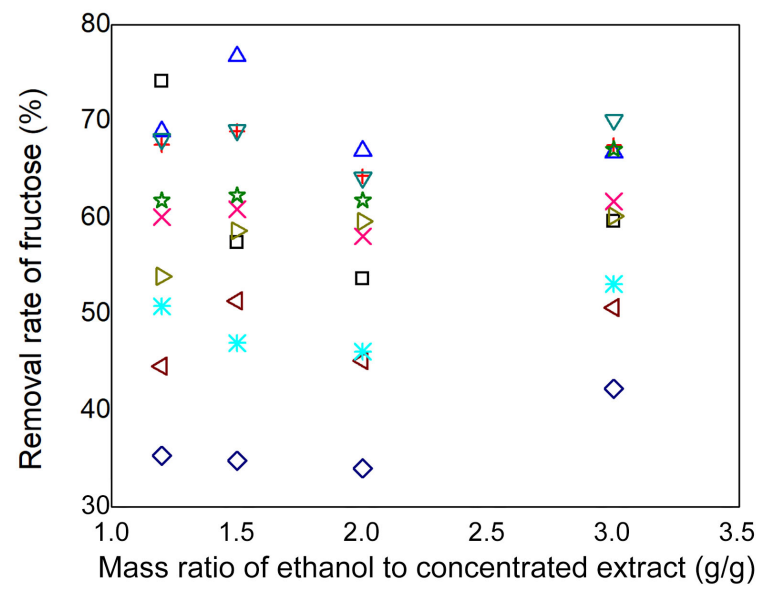

(a) fructose

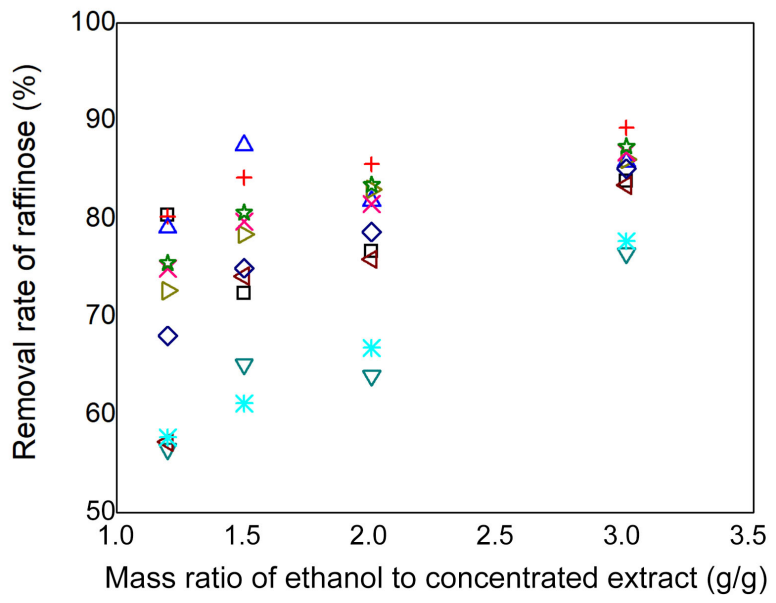

(c) raffinose

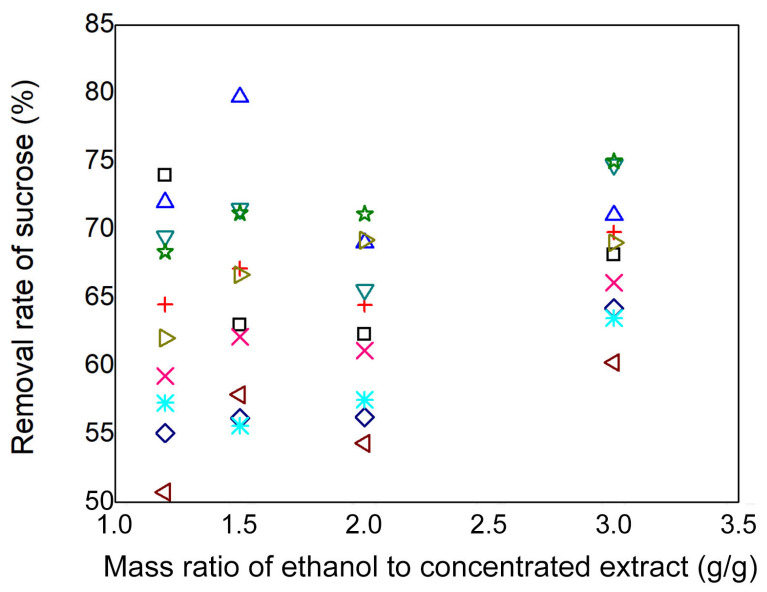

(b) sucrose

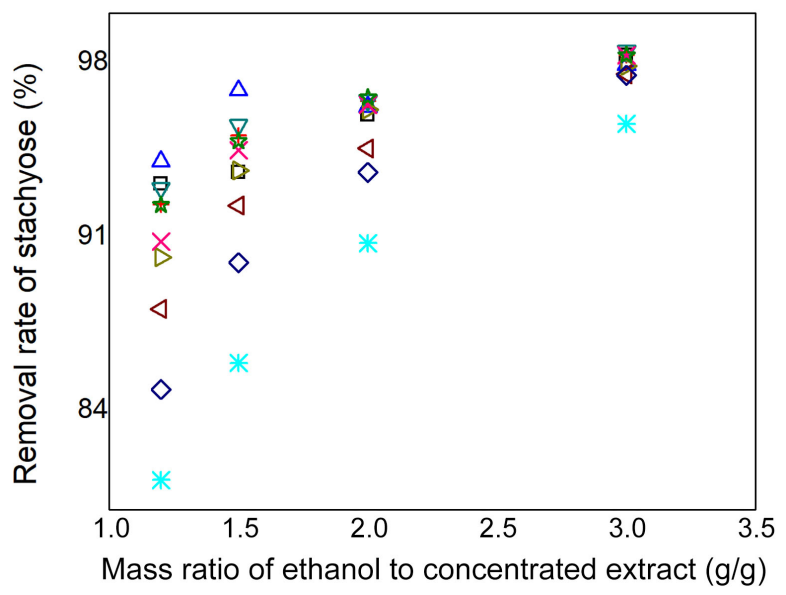

(d) stachyose

Figure 7. Results of carbohydrate removal rate of supernatant. $\square$ 200525; + 180927; $\triangle 181001 ; \nabla 180901 ; \triangleleft 200501 ; \triangleright$

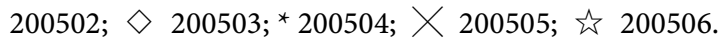

Table 6. Regression coefficient and analysis of variance results.

\begin{tabular}{|c|c|c|c|c|c|c|c|c|c|c|c|c|c|c|c|c|}
\hline Process index & & Constant & ECR & Conductivity & $\mathrm{pH}$ & $\begin{array}{l}\text { Fructose } \\
\text { content }\end{array}$ & $\begin{array}{c}\text { Raffinose } \\
\text { content }\end{array}$ & $\begin{array}{c}\text { Stachyose } \\
\text { content }\end{array}$ & $\begin{array}{c}\text { Purity of } \\
\text { Danshensu }\end{array}$ & $\begin{array}{l}\text { Purity of } \\
\text { protocatechuic } \\
\text { aldehyde }\end{array}$ & $\begin{array}{l}\text { Purity } \\
\text { of } \\
\text { Caffeic } \\
\text { acid }\end{array}$ & $\begin{array}{c}\text { Purity of } \\
\text { Rosmarinic } \\
\text { acid }\end{array}$ & $\begin{array}{c}\text { Purity of } \\
\text { Lithospermic } \\
\text { acid }\end{array}$ & $\begin{array}{l}\text { Purity of } \\
\text { Salvianolic } \\
\text { acid B }\end{array}$ & $\mathrm{R}^{2}$ & $\mathrm{R}_{\mathrm{adj}}^{2}$ \\
\hline \multirow{2}{*}{$\begin{array}{l}\text { Purity of } \\
\text { Danshensu }\end{array}$} & $\begin{array}{l}\text { Regression } \\
\text { coefficient }\end{array}$ & 1.051 & 0.140 & & & 0.467 & & & & & 0.618 & & & & 0.7436 & 0.7222 \\
\hline & $P$ value & & $<0.0001$ & & & $<0.0001$ & & & & & 0.0004 & & & & & \\
\hline \multirow{2}{*}{$\begin{array}{l}\text { Purity of } \\
\text { protocatechuic } \\
\text { aldehyde }\end{array}$} & $\begin{array}{l}\text { Regression } \\
\text { coefficient }\end{array}$ & 0.051 & 0.035 & & & & -0.113 & & & 0.144 & & & 0.099 & -0.047 & 0.8185 & 0.7918 \\
\hline & P value & & $<0.0001$ & & & & $<0.0001$ & & & $<0.0001$ & & & $<0.0001$ & 0.0020 & & \\
\hline \multirow{2}{*}{$\begin{array}{c}\text { Purity of } \\
\text { Caffeic acid }\end{array}$} & $\begin{array}{l}\text { Regression } \\
\text { coefficient }\end{array}$ & 0.093 & 0.018 & & & & & -0.017 & & & 0.103 & & 0.050 & -0.043 & 0.8163 & 0.7893 \\
\hline & $P$ value & & $<0.0001$ & & & & & 0.0024 & & & $<0.0001$ & & $<0.0001$ & $<0.0001$ & & \\
\hline $\begin{array}{c}\text { Purity of } \\
\text { Rosmarinic acid }\end{array}$ & $\begin{array}{l}\text { Regression } \\
\text { coefficient }\end{array}$ & 1.251 & 0.188 & & & & & & & & 0.562 & 0.932 & & & 0.8973 & 0.8888 \\
\hline \multirow{2}{*}{$\begin{array}{c}\text { Purity of } \\
\text { Lithospermic } \\
\text { acid }\end{array}$} & $\begin{array}{l}\text { Regression } \\
\text { coefficient }\end{array}$ & 0.329 & 0.078 & & & 0.236 & -0.271 & & & & & & 0.404 & & 0.8121 & 0.7907 \\
\hline & $P$ value & & 0.0002 & & & $<0.0001$ & 0.0011 & & & & & & $<0.0001$ & & & \\
\hline
\end{tabular}




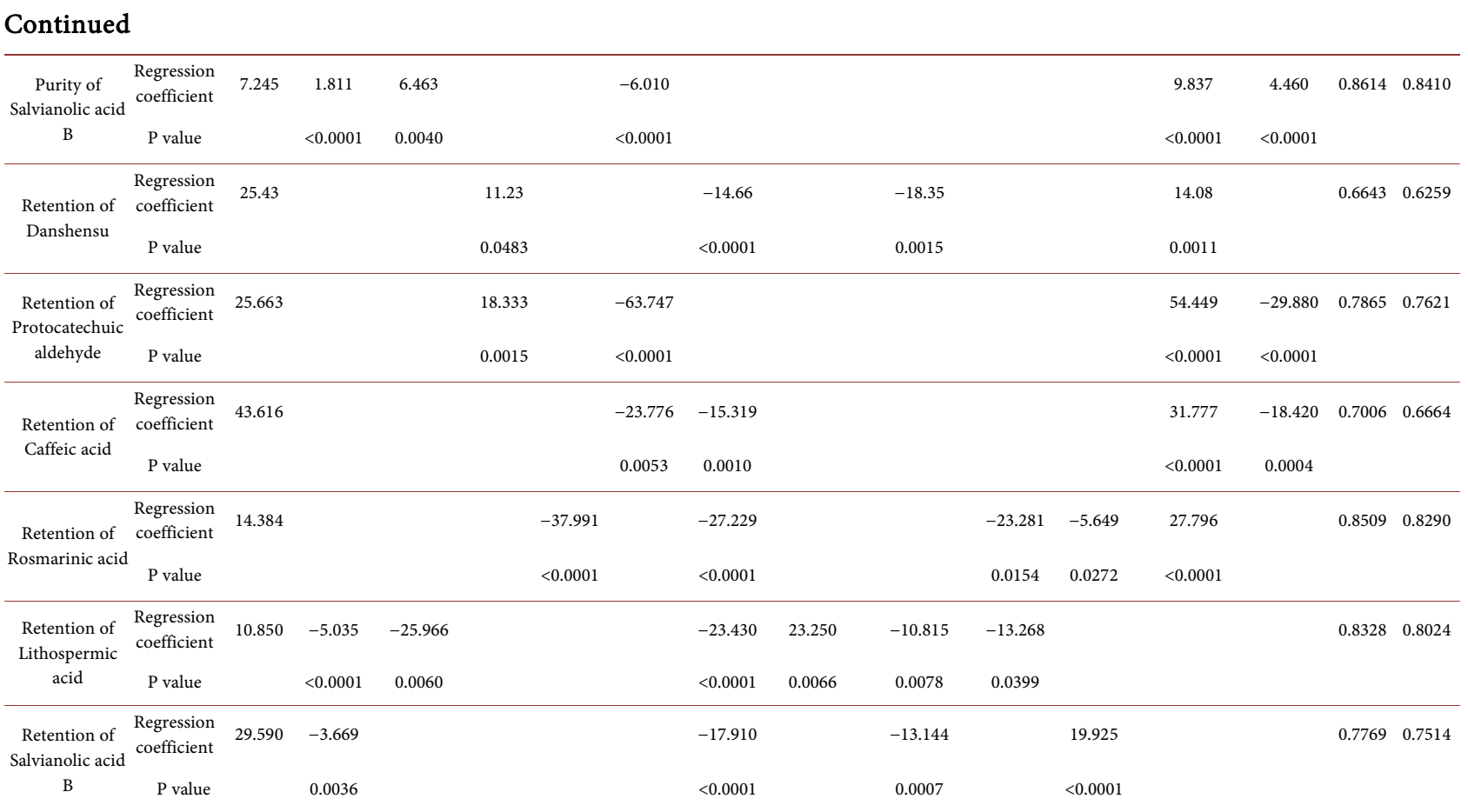

Higher salvianolic acid B purity in the concentrate can result in lower retention rate of protocatechuic aldehyde and caffeic acid, lower purity of protocatechuic aldehyde and caffeic acid, but higher purity of salvianolic acid B purity in the supernatant. Higher lithospermic acid purity in the concentrate led to higher purity and retention rate of multiple phenolic acids. Higher purity of caffeic acid, rosmarinic acid, and protocatechuic aldehyde can lead to higher phenolic acid purity in the supernatant, but at most occasions can result in lower phenolic acid retention rate. Higher Danshensu purity in the concentrate can result in higher retention rate of lithospermic acid.

\section{Conclusion}

In this work, multiple batches of Salvia miltiorrhiza concentrate were prepared and treated with ethanol precipitation. Dry matter content, $\mathrm{pH}$ value, conductivity and water content of the concentrates and supernatants were measured. Most of stachyose was removed in the ethanol precipitation process. Fructose, raffinose and sucrose were also significantly removed. With the increase of ethanol addition amount, the purity of phenolic acids in the supernatant increased, but the retention of lithosperimic acid and salvianolic acid B decreased. The conductivity and $\mathrm{pH}$ value of concentrated extract have a relatively small effect on ethanol precipitation indices. With a higher fructose, raffinose, or stachyose content in the concentrated extract, a lower retention rate of phenolic acids will be obtained on most occasions. Sucrose content in the concentrated extract showed little effect on process indices. The purity of phenolic acids in the concentrated will affect the purity and retention rate of phenolic acids in the supernatants. The results of this work indicated that the sugar content in the concen- 
trate needs to be monitored in industry due to their influences on ethanol precipitation process indices.

\section{Acknowledgements}

We thank Miss Zhang Xiaohui and Miss Chen Yu for their help in the experiments.

\section{Funding}

This work was supported by the National S\&T Major Project of China (2018ZX09201011-002) and the Basic Public Welfare Research Program of Zhejiang Province (LGG18H280001). Funders had no role in study design, collection, analysis and interpretation of data and in writing the manuscript.

\section{Conflicts of Interest}

The authors declare no conflicts of interest regarding the publication of this paper.

\section{References}

[1] Tai, Y.N., Qu, H.B. and Gong, X.C. (2021) Design Space Calculation and Continuous Improvement Considering a Noise Parameter: A Case Study of Ethanol Precipitation Process Optimization for Carthami Flos Extract. Separations, 8, 74. https://doi.org/10.21203/rs.3.rs-305170/v1

[2] Tai, Y., et al. (2020) Research Progress on the Ethanol Precipitation Process of Traditional Chinese Medicine. Chinese Medicine, 15, Article No. 84 https://doi.org/10.1186/s13020-020-00366-2

[3] Zhang, L., et al. (2012) Solubilities of Protocatechuic Aldehyde, Caffeic Acid, d-Galactose, and d-Raffinose Pentahydrate in Ethanol-Water Solutions. Journal of Chemical \& Engineering Data, 57, 2018-2022. https://doi.org/10.1021/je300323g

[4] Gong, X., et al. (2012) Solubility of Xylose, Mannose, Maltose Monohydrate, and Trehalose Dihydrate in Ethanol-Water Solutions. Journal of Chemical \& Engineering Data, 57, 3264-3269. https://doi.org/10.1021/je300885g

[5] Gong, X., Wang, S. and Qu, H. (2011) Solid-Liquid Equilibria of D-Glucose, D-Fructose and Sucrose in the Mixture of Ethanol and Water from 273.2 K to 293.2 K. Chinese Journal of Chemical Engineering, 19, 217-222. https://doi.org/10.1016/S1004-9541(11)60157-2

[6] Gong, X., et al. (2013) Separation Characteristics of Ethanol Precipitation for the Purification of the Water Extract of Medicinal Plants. Separation and Purification Technology, 107, 273-280. https://doi.org/10.1016/j.seppur.2013.01.029

[7] Pan, J.J., et al. (2020) Optimization of Membrane Dispersion Ethanol Precipitation Process with a Set of Temperature Control Improved Equipment. Scientific Reports, 10, Article No. 19010. https://doi.org/10.1038/s41598-020-75900-1

[8] Wang, J. (2007) The Applications of Process Analytical Technology in Salvia Miltiorrhiza Ethanol Precipitation and 'YangWEI' Granules Spraying and Drying Granulation. Zhejiang University, Zhejiang.

[9] Yu, X. (2008) The Quality Control Technique Research of Danshen Extration and Danshen Precipitation. Zhejiang University, Zhejiang. 
[10] Wang, Y., et al. (2011) Study on Chemical Changes of Salvianolic Acid B and Lithospermic Acid Aqueous under Conditions of High Temperature and High Pressure. Zhongguo Zhong yao za zhi = Zhongguo zhongyao zazhi = China Journal of Chinese Materia Medica, 36, 434-438.

[11] Mao, S.-J., et al. (2003) Studies on Variation of Danshensu Content in Accelerated Stability Tests. Zhongguo Zhongyao Zazhi, 28, 220-222.

[12] Pan, J.J., et al. (2020) Ethanol Precipitation of Codonopsis Radix Concentrate with a Membrane Dispersion Micromixer. Journal of Cleaner Production, 251, Article ID: 119633. https://doi.org/10.1016/j.jclepro.2019.119633

[13] Yan, A., Gong, X. and Qu, H. (2012) Method for Discriminating Key Quality Control Indicators of Concentrated Solution before Traditional Chinese Medicine Ethanol Precipitation. Zhongguo Zhong yao za zhi= Zhongguo $z$ hongyao zazhi $=$ China Journal of Chinese Materia Medica, 37, 1558-1563.

[14] Zhang, H., et al. (2011) Study on Quality Indicators for Concentration Process of Supernatant Obtained in First Ethanol Precipitation in Production of Danshen Injection. Zhongguo Zhong yao za zhi = Zhongguo zhongyao zazhi = China Journal of Chinese Materia Medica, 36, 1436-1440.

[15] Cao, J., et al. (2008) Determination of Fifteen Bioactive Components in Radix et Rhizoma Salviae Miltiorrhizae by High-Performance Liquid Chromatography with Ultraviolet and Mass Spectrometric Detection. Biomedical Chromatography, 22, 164-172. https://doi.org/10.1002/bmc.911

[16] Chen, Z.Q., et al. (2021) Simulataneous Determination of Seven Saccharides in the Intermediates of Danshen Chuanxiongqin Injection by HPLC-ELSD. The Chinese Journal of Modern Applied Pharmacy, 38, 1349-1353.

[17] Gong, X., Wang, S. and Qu, H. (2011) Comparison of Two Separation Technologies Applied in the Manufacture of Botanical Injections: Second Ethanol Precipitation and Solvent Extraction. Industrial \& Engineering Chemistry Research, 50, 7542-7548. https://doi.org/10.1021/ie2004972 